\title{
Power Consumption Analysis and Experimental Study on the Kneading and Cutting Process of Licorice Stem in Horizontal Total Mixed Ration Mixer
}

\author{
Wentao Li ${ }^{1}$, Baoqin Wen ${ }^{1,2, *}$, Pengxiang Song ${ }^{1}$, Yameng Shi ${ }^{1}$, Jie Zhang ${ }^{1,3, *}$, Jingbin Li ${ }^{1,2}$, Junpeng Liang ${ }^{1}$, \\ Tianyang $\mathrm{Li}^{1}$ and Beichuan $\mathrm{Qu}{ }^{1}$ \\ 1 College of Mechanical and Electrical Engineering, Shihezi University, Shihezi 832000, China; \\ 20192109023@stu.shzu.edu.cn (W.L.); songpx@stu.shzu.edu.cn (P.S.); sym@stu.shzu.edu.cn (Y.S.); \\ lijingbin@shzu.edu.cn (J.L.); ljp@stu.shzh.ednu.cn (J.L.); litianyang@stu.shzu.edu.cn (T.L.); \\ qbc@stu.shzu.edu.cn (B.Q.) \\ 2 Xinjiang Production and Construction Corps Key Laboratory of Modern Agricultural Machinery, \\ Shihezi 832000, China \\ 3 Institute of Agricultural Mechanization, Xinjiang Academy of Agricultural Sciences, Urumqi 830000, China \\ * Correspondence: wbq1980@shzu.edu.cn (B.W.); xjwszj0230@sina.com (J.Z.); Tel.: +86-159-0993-8318 (B.W.)
}

check for

updates

Citation: Li, W.; Wen, B.; Song, P.; Shi, Y.; Zhang, J.; Li, J.; Liang, J.; Li, T.; $\mathrm{Qu}, \mathrm{B}$. Power Consumption Analysis and Experimental Study on the Kneading and Cutting Process of Licorice Stem in Horizontal Total Mixed Ration Mixer. Processes 2021, 9 , 2108. https://doi.org/10.3390/ pr9122108

Academic Editor: Bor-Yih Yu

Received: 25 October 2021

Accepted: 19 November 2021

Published: 24 November 2021

Publisher's Note: MDPI stays neutral with regard to jurisdictional claims in published maps and institutional affiliations.

Copyright: (C) 2021 by the authors Licensee MDPI, Basel, Switzerland. This article is an open access article distributed under the terms and conditions of the Creative Commons Attribution (CC BY) license (https:/ / creativecommons.org/licenses/by/ $4.0 /)$.
Abstract: Aiming at the problems of high-power consumption and insufficient kneading and cutting of roughage in the total mixed ration mixer. In this paper, licorice stems were taken as experimental objects, the horizontal twin-shaft TMR mixer was used to carry out the experimental study. It should be as brief as possible and concise. Through the kneading and cutting process power analysis, determine the influencing factors of kneading and cutting power consumption. The auger speed, processing time and blade type were taken as experimental factors, with standard straw length rate and power consumption as indicators, Box-Behnken test with three factors and three levels was carried out, analysis of variance was performed on the test results, the results show that the significant effect of each factor on the standard grass length is processing time, blade type and auger speed in descending order. The significance of the influence on power consumption from large to small is auger speed, processing time and blade type. The response surface analysis and parameter optimization were carried out, the results show that the auger speed is $20 \mathrm{r} / \mathrm{min}$, the processing time is $29 \mathrm{~min}$, and the blade type is quincunx blade. At this time, the standard straw length was $82.634 \%$; Power consumption $4525.815 \mathrm{~kJ}$, TMR mixer performance reached the best. The results can provide a theoretical basis for the subsequent research and development of TMR mixer.

Keywords: licorice stem; kneading power consumption; standard straw length rate; experimental study

\section{Introduction}

Xinjiang is one of the five pastoral areas in China. With the development of animal husbandry in Xinjiang, the shortage of forage grass resources has become increasingly serious, which has restricted the development of animal husbandry in Xinjiang [1,2]. Glycyrrhiza is a perennial leguminous plant, whose aboveground stems have high medicinal value and feeding value, and can be used as forage grass for livestock and poultry [3-6]. The quality and yield of local licorice in Xinjiang ranked first in China, and its supply accounted for more than $50 \%$ of the country [7]. Licorice stem used for livestock and poultry feeding can effectively alleviate the lack of forage resources in Xinjiang. Total mixture ration mixer is a machine that integrates cutting, rubbing, and mixing [8,9]. Total mixed ration (TMR) $[10,11]$ can significantly improve the palatability and feeding rate of roughage, while reducing labor intensity, and become the mainstream in cattle and sheep breeding. Using TMR blender to knead and cut licorice stem efficiently is the key to introduce licorice stem into 
TMR feeding. Reducing the energy consumption of machines performing cutting, rubbing, and mixing processes is a current scientific trend that is being developed today [12-14].

In view of the research status of TMR mixer and power consumption, Wen Baoqin et al. [15] designed a pieceally-spiral rope-cutting device for licorice stem and carried out response surface test. The quadratic multinomial influence model of grain size, breakage rate and energy consumption per unit mass on four factors and three levels was established. The influence trends of auger speed, processing time, filling coefficient, blade and bottom shell clearance on grain size, breakage rate and energy consumption per unit mass of liquorice stalk after rubbing and cutting were analyzed. Li Jingbin et al. [16] designed a self-walking dual-axis horizontal TMR mixer with spiral structure for large-scale mutton sheep feeding, and carried out a comparative feeding test of multi-wave sheep. The weight gain of the experimental group was increased by $7.81 \%$ compared with that of the control group, achieving better mixing and feeding effects. The dual-axis horizontal TMR mixer designed and developed by Wang Defu et al. [17] took silage corn, corn straw, alfalfa hay, corn flour and salt as test objects. The test showed that the rotational speed and filling coefficient were the main factors affecting the mixing strength of materials. Uzi Moallem et al. [18] used a full mixed diet prepared by different mixers to feed multiparous Israeli Holstein cattle and evaluate their milk yield, days of lactation, parity, and body weight. The results showed that the total mixed ration produced by different total mixed ration mixers had effects on the performance of dairy cows, and the importance of preparation machinery on the quality of TMR should be emphasized. Lato Pezo et al. [19] studied the mechanism of particle tracking in particle flow by DEM analysis, and applied it to static mixing mixer and drum mixer of corn flour. In order to reduce the mixing time and energy consumption, the particle mixing performance of ground corn flour was studied in static mixer and drum mixer. Marczuk A et al. [20] designed a horizontal mixer and carried out theoretical analysis on its mixing mechanism. The experimental results were carried out by taking the changes of rotational speed, pitch, and density of the mixing shaft as factors. The results of this theoretical study provide structural and technical analysis factors for determining the power consumption of the unit of work driver during the mixer design phase. Applying the developed mathematical model can reduce the cost of designing, manufacturing, and optimizing the operation of the belt mixer.

In order to explore the optimal parameter combination in the working process of TMR mixer, improve the kneading and cutting performance of TMR mixer, and improve the forage utilization rate of livestock and poultry farms. Taking horizontal dual-axis TMR mixer as the research object, the material in the working process was theoretically analyzed, and the experimental factors affecting the power consumption in the working engineering of TMR mixer were obtained. The stem of Xinjiang Uralcyrrhiza uralensis was used as the experimental object, in order to provide reference for the subsequent development of new TMR blender.

\section{The Structure and Working Principle of the Machine}

\subsection{Structure of the Whole Machine}

The overall structure of horizontal dual-axis TMR mixer is shown in Figure 1, which is mainly composed of kneading and shredding device, hydraulic control system and weighing system. Kneading and cutting device mainly consists of reduction motor, reducer, elastic coupling, face type spiral auger (auger shaft tube, spiral blade, blade), fixed knife, material box and other components; hydraulic control system is mainly composed of control cabinet, hydraulic cylinder, motor, pressure gauge, flux valve, discharge port hydraulic cylinder, feed port hydraulic cylinder, feed hopper, discharge door and so on; the weighing system is mainly composed of weighing sensor and weighing display. 

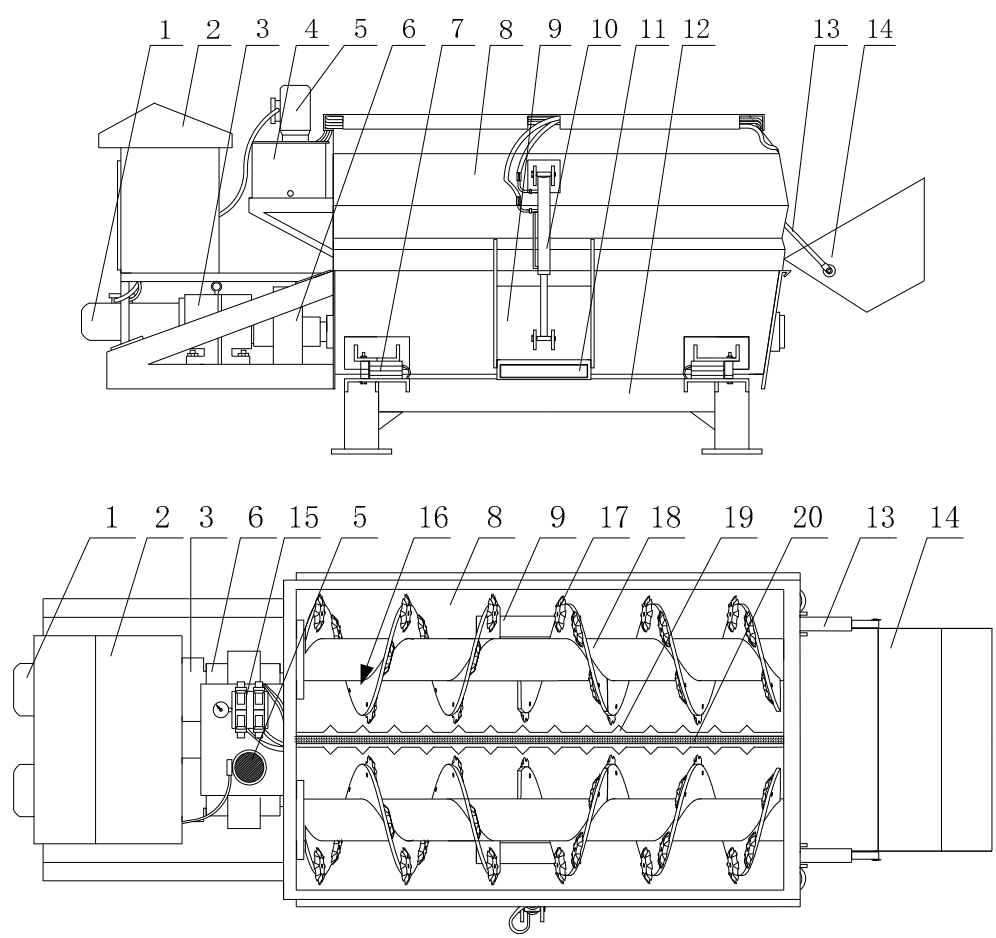

(1) Motor, (2) Control cabinet. (3) Reducer. (4) Coupling. (5) Hydraulic motor. (6) Coupling. (7) Weighing system. (8) Discharging port hydraulic cylinder. (11) Strong magnet. (12) Frame. (13) Feed hopper. (15) Hydraulic system control flux valve. (16) Spiral Blade. (17) Auger shaft tube. (19) Fixed tool. (20) The beam.

Figure 1. Schematic diagram of horizontal two-axis TMR mixer mechanism.

\subsection{The Working Principle}

The main purpose of the horizontal double-axis TMR mixer is to mince the licorice stems to make the standard straw length meet the requirements of TMR feeding, and to knead and break the licorice stems to make the processed licorice stems soft and fluffy and easy for ruminants to eat. The working process is shown in Figure 2. The power is provided by the motor during the work. Two screw augers rotate in the middle, and the fixed knife is placed on both sides of the beam of the material box. The grass bale of licorice straw is placed in the feeding mouth, and the grass bale of licorice straw is put into the feeding box through hydraulic control. The weight of the added material is measured by the weighing system. Because of the auger's centering design, the auger tranches the licorice stem horizontally, forming a pile when transported to the middle. After passing the stacking angle of the chopped licorice stem, the upper licorice stem slides by gravity along the stacking angle to the sides. This repeatedly realizes the shredding and rolling of the licorice stem, when the processing of the licorice stem reaches the standard grass length rate, through hydraulic control, open the outlet of the lower part of the spiral auger in the middle of the material box, and discharge the material. 


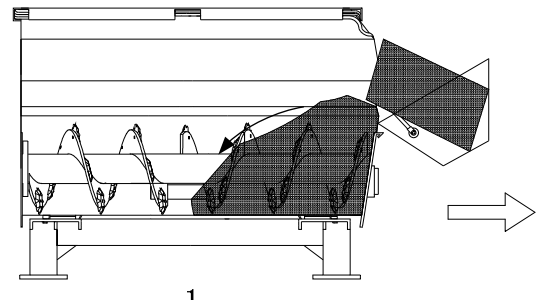

1

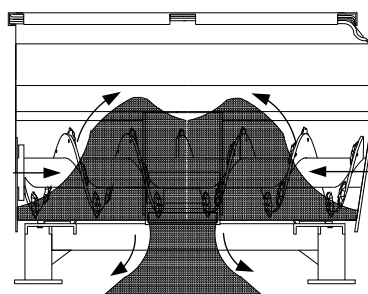

4
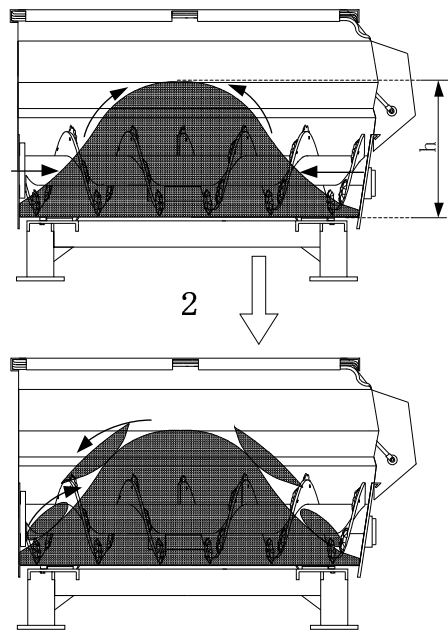

3

Figure 2. Schematic diagram of horizontal two-axis TMR mixer.

\section{The Structure and Working Principle of the Machine}

\subsection{Key Parameters of Auger Are Determined}

(1) Length of auger shaft. In this paper, according to the standard series in the "Mechanical Engineering Manual" and the existing test conditions, the auger length $L=2235 \mathrm{~mm}$.

(2) Central axis diameter. The calculation formula of auger center axis [21-23] is

$$
d=(0.02 \sim 0.4) L
$$

where $d$ represents the diameter of the central axis, $\mathrm{mm} ; L$ represents auger length, $\mathrm{mm}$.

If the diameter of the central axis is too large, the space in the spiral groove becomes smaller. When the crushed licorice stem moves in a narrow space, the accumulation amount is large, its passability is poor, and the degree of mutual extrusion between materials is high. The friction resistance between material and material, material and spiral blade and casing increases, resulting in the standard straw length ratio of licorice stem decreases and power consumption increases. The central shaft diameter is too small, the strength and stiffness of auger cannot meet the requirements of use. Take the central axis diameter $D=720 \mathrm{~mm}$.

(3) Outer diameter of spiral blade. The outer diameter $D$ of the spiral blade is one of the important parameters determining the kneading and conveying of the spiral auger, which is directly related to the performance of the mixer and the productivity [24].

$$
Q=\frac{60 V \varphi \gamma}{\sum t}
$$

where, $V$ is the volume of mixing chamber $\left(\mathrm{m}^{3}\right) ; \varphi$ is the material filling coefficient, generally ranging from $0.7-1.0 ; \gamma$ is bulk density of material $\left(\mathrm{kg} / \mathrm{m}^{3}\right) ; \sum t$ is the time required for the mixing period.

The outer diameter of auger was calculated as [25]:

$$
D=0.277 \sqrt[3]{\frac{Q}{\varphi K \lambda n}}
$$

where $Q$ is productivity of mixer $(\mathrm{kg} / \mathrm{h}) ; \varphi$ is material filling coefficient; $\lambda$ is the bulk density of materials $\left(\mathrm{kN} / \mathrm{m}^{3}\right) ; n$ is auger speed $(\mathrm{r} / \mathrm{min})$. Take the outer diameter of spiral blade $D=1650 \mathrm{~mm}$. 
(4) Pitch of spiral blade. The calculation formula of pitch is

$$
H=(0.5 \sim 2.2) D
$$

where $H$ represents the pitch of spiral blade, $\mathrm{mm}$;

Pitch not only determines the motion speed of the material, but also determines the force of the spiral blade and the housing. The relationship between the push speed of the spiral blade and the pitch is as follows:

$$
v=\frac{n H}{60}
$$

In the formula, $n$ represents the screw shaft speed, $\mathrm{r} / \mathrm{min} ; v$ represents the push speed of the spiral blade, $\mathrm{r} / \mathrm{min}$.

From Equation (5), it can be seen that with the increase of pitch, the motion speed of material increases, and productivity can be improved. At the same time, when the pitch is large, the space in the spiral groove becomes larger, and the crushed licorice stems move in a loose state. The degree of mutual extrusion and winding is weakened, which effectively reduces the backlog degree of materials between the blade and the chassis. However, at this time, the flow kinetic energy of materials is large, and the power consumption increases. Therefore, the pitch is set as $S=380 \mathrm{~mm}$

(5) Helix angle of spiral blade. The formula for helix angle of spiral blade is [26]:

$$
\delta=\left(45^{\circ}+\frac{\theta}{2}\right)
$$

where, $\delta$ represents the helical Angle of the helical blade, ${ }^{\circ} . \theta$ is the friction angle between material and spiral blade, ${ }^{\circ}$.

Too large or too small helical angle of helical blade will weaken convective mixing in the working process of TMR mixer, and even lead to screw blockage, thus reducing the quality of feed kneading, cutting, and mixing. Take the helix angle $\delta=50^{\circ}$ of the spiral blade.

\subsection{Dynamics Analysis of Stem Microelement in Rubbing and Cutting Licorice}

\subsubsection{Velocity Analysis}

Speed analysis of material microelement in spiral groove of spiral auger was carried out [27], as shown in the figure. In the figure, is the relative velocity of the material element body, is the implicated velocity of the material element body, is the absolute velocity of the material element body, then

$$
v_{a}=v_{r}+v_{e}
$$

Among them

$$
\left\{\begin{array}{c}
v_{e}=\omega r_{1}=\frac{\pi r_{1} n}{30} \\
v_{r}=\frac{v_{e} \sin \beta}{\sin (\alpha+\beta)}=\frac{\pi r_{1} n \sin \beta}{30 \sin (\alpha+\beta)} \\
v_{a}=\frac{v_{e} \sin \alpha}{\sin (\alpha+\beta)}=\frac{\pi r_{1} n \sin \alpha}{30 \sin (\alpha+\beta)}
\end{array}\right.
$$

where, $\alpha$ is the spiral rising angle of spiral blade, ${ }^{\circ} ; \beta$ is the traction angle of microelement motion, ${ }^{\circ} ; r_{1}$ is the radius of the spiral blade, $\mathrm{mm}$. The relation between pitch, radius, and helix angle of spiral blade is

$$
\alpha=\arctan \frac{H}{2 \pi r_{1} n}
$$

According to Equation (8), the relative velocity, implicated velocity and absolute velocity of the material element are related to the rotational speed of the auger. 


\subsubsection{Motion Analysis}

The force of licorice stem microelement under the action of TMR mixer auger [28] is shown in Figure 3. Figure 3 shows that the positive pressure $F_{1}$ at the back of the spiral blade is

$$
F_{1}=P R_{2} h d z
$$

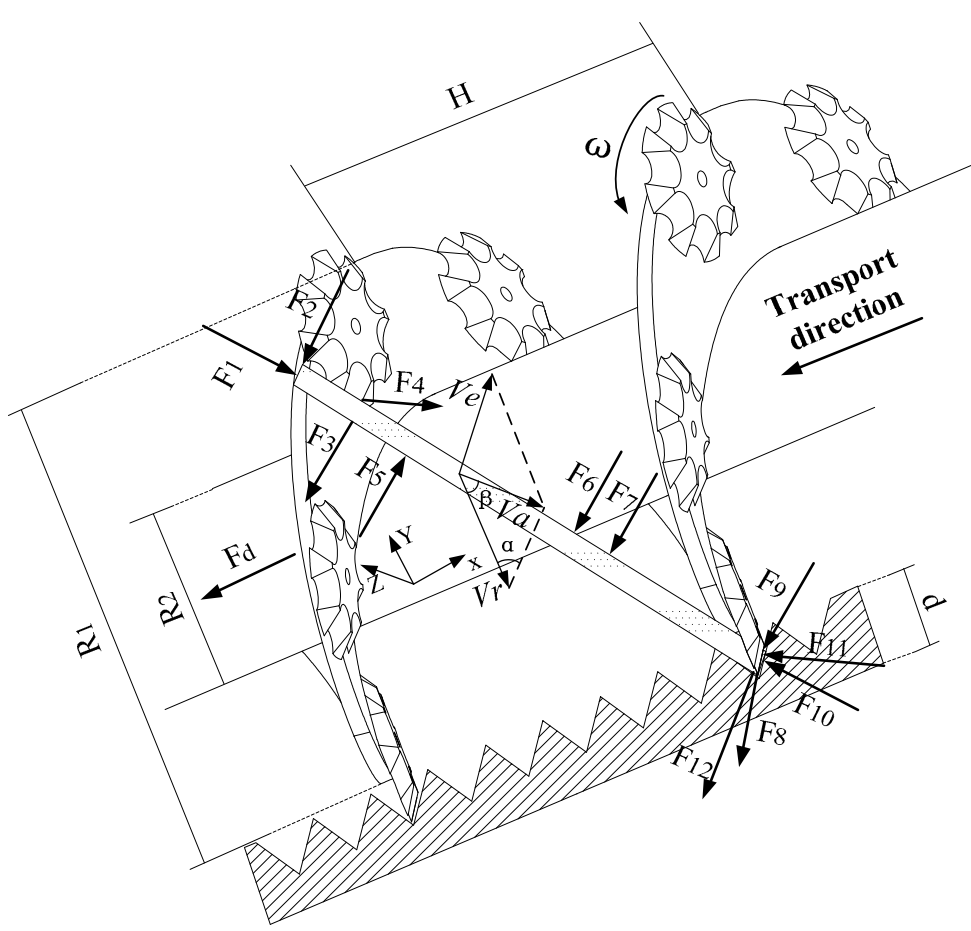

Figure 3. Schematic diagram of force on materials.

The friction force $F_{2}$ on the back side of the spiral blade is

$$
F_{2}=f_{a} P R_{2} h d z
$$

The friction force $F_{3}$ between the material cell and the material below is

$$
F_{3}=f_{b} P H d z
$$

The friction force $F_{4}$ between the material element body and the casing is

$$
F_{4}=f_{c}\left(P H d z+\rho d z H R_{2} h a_{n}\right)
$$

The thrust force $F_{5}$ of subsequent materials in the forward direction is

$$
F_{5}=P H R_{2} h
$$

The resistance of the material in front to the material element body $F_{6}$ is

$$
F_{6}=\left(P+\frac{\partial P}{\partial z}\right) H R_{2} h
$$

The friction force $F_{7}$ of the material above the material cell is

$$
F_{7}=f_{b} P H R_{2} d z
$$


The shear force $F_{8}$ of the blade on the cell is

$$
F_{8}=A \tau
$$

The positive pressure $F_{9}$ on the bearing surface of the spiral blade is

$$
F_{9}=P R_{2} h d z+F_{d}
$$

Friction force $F_{10}$ on the confined surface of spiral blade is

$$
F_{10}=f_{a}\left(P R_{2} h d z+F_{d}\right)
$$

The supporting force of fixed knife on micro-element body $F_{11}$ is

$$
F_{11}=P d h d z
$$

The friction force $F_{12}$ of the fixed knife on the micro-element is

$$
F_{12}=f_{d} P d h d z
$$

In Formulas (12)-(21), $P$ is the pressure on the material, $\mathrm{P}_{\mathrm{a}} ; H$ is the height of the material, $\mathrm{mm} ; z$ is the conveying length of material, $\mathrm{mm} ; \rho$ is the density of material, $\mathrm{kg} / \mathrm{m}^{3}$; $a_{n}$ is the acceleration of material, $\mathrm{m} / \mathrm{s}^{2} ; f_{a}$ is the friction coefficient between the material and the spiral auger shaft and the material box shell; $f_{b}$ is the friction coefficient between materials; $f_{c}$ is the friction coefficient between material and spiral blade and blade; $f_{d}$ is the friction coefficient between the material and the fixed knife.

The power consumption of horizontal dual-axis TMR mixer during operation mainly includes: the work consumed by the friction between the material and the casing surface, the work consumed by the friction between the material and the pressure surface of the spiral blade and the back of the blade, the work consumed by friction between material and spiral auger shaft, the work consumed by twisting, squeezing and friction between crushed licorice stem, and the work consumed by blade cutting licorice stem.

(1) The work consumed by the micro-increment in the $z$ direction between the material and the casing (W-type casing) is:

$$
E_{1}=F_{4} v_{a} t
$$

The double integral of spiral blade height and conveying length can be obtained

$$
E_{11}=\left(\int_{0}^{z} \int_{0}^{H} F_{4} v_{a} R_{2} h d z\right) t
$$

(2) The work consumed between the material and the pressure surface of the blade and the back of the blade as well as the fixed knife in the micro increment in the $z$ direction is

$$
E_{2}=\left(\left(F_{2}+F_{9}+F_{11}\right) v_{r}\right) t
$$

The double integral on the height of the spiral blade and the conveying length can be obtained

$$
E_{22}=\left(\int_{0}^{z} \int_{0}^{H}\left(\left(F_{2}+F_{9}+F_{11}\right) v_{r}\right) R_{2} h d z\right) t
$$

(3) The work consumed by the friction between the material and the auger shaft is

$$
E_{3}=F_{c} v_{r} t
$$

The double integral on the height of the spiral blade and the conveying length can be obtained

$$
E_{33}=\left(\int_{0}^{z} \int_{0}^{H} F_{c} v_{r} R_{2} h d z\right) t
$$


(4) The work consumed by friction between the material and the fixed knife is

$$
E_{4}=F_{12} v_{r} t
$$

Double integration on the fixed cutter width and conveying length can be obtained

$$
E_{44}=\left(\int_{0}^{z} \int_{0}^{d} F_{12} v_{r} h d z\right) t
$$

(5) The work consumed by the shearing action between the material and the blade on the auger

$$
E_{5}=F_{8} v_{r} t
$$

The double integral on the height of the spiral blade and the conveying length can be obtained

$$
E_{55}=\left(\int_{0}^{z} \int_{0}^{H} F_{8} v_{r} R_{2} h d z\right) t
$$

(6) The work consumed by the interaction between materials.

After rubbing and cutting, the licorice stem itself is loose and cannot maintain its shape and original size. Due to the gap between the materials, when the external pressure, the gap between the materials becomes smaller and smaller, so that the licorice stem is compressed, and the density increases. When the external pressure reaches a certain value, there will be clustering and other phenomena. Therefore, the movement of the rotted licorice stem in the spiral groove is complicated, and the material group is extruded, mixed, and wound each other in the processing process, thus consuming part of the work. Thus, so far, it is impossible to accurately calculate the consumption of this part of work mathematically, and it is usually considered in the form of correction coefficient [29].

(7) The total power consumption of horizontal TMR mixer in the process of kneading, cutting, and conveying is

$$
E=k\left(E_{11}+E_{22}+E_{33}+E_{44}+E_{55}\right)
$$

where, $k$ is the power coefficient consumed by crushing the interaction between liquorice stems.

According to Equations (12)-(33), it can be seen that the power consumption is related to the processing time and shear force.

\section{Liquorice Kneading and Cutting Device Kneading Test}

\subsection{Test Material and Equipment}

The stems of Glycyrrhiza uralensis from Yushugou Village, Hutubi County, Xinjiang, China, which is the most representative area in the north of Tianshan Mountain, were used as experimental materials. Sartorius moisture meter MA100C-000230V1 (Suzhou gold diamond Sartorius level agent Suzhou, China) moisture tester was used to measure 10 groups of licorice stems with $2 \mathrm{~g}$ in each group, and the average moisture content was $5.98 \%$. The length, width and height of straw bale are $1000 \mathrm{~mm}, 500 \mathrm{~mm}$ and $400 \mathrm{~mm}$ measured by tape measure. The average mass of straw bales measured by $30 \mathrm{~kg}$ range electronic scale is $16 \mathrm{~kg}$. Combined with the material box volume of $4 \mathrm{~m}^{3}, 14$ bundles of licorice stalks are needed for the filling coefficient of $70 \%$. The most commonly used circular blade and quincunx blade in TMR blender on the market are selected, and 100\% round blade, $100 \%$ quincunx blade, unit lead outer spiral quincunx blade and adjacent unit lead outer spiral round blade are respectively selected. Siemens G120C inverter (Siemens, Erlangen, Germany) to adjust motor speed; STARTER_V54_HF2_Program software (Siemens, Erlangen, Germany) computer is installed to test the current, voltage, motor torque and motor frequency. JM-85003 electronic balance (JM Katawala, Itwari, Maharashtra, India) to take stem samples, etc. The three blade installation forms are shown in Figure 4. Subsection. 


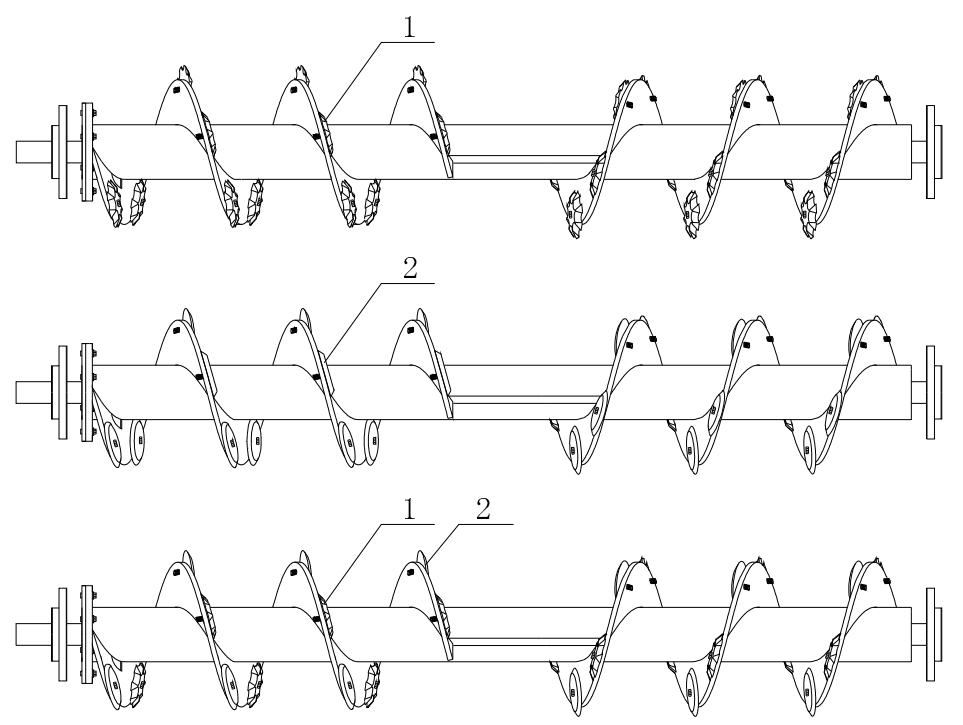

(1) Quincunx blade. (2) Round blade.

Figure 4. Blade installation form.

\subsection{Trial Evaluation Indicators}

According to the feed processing requirements [30], the standard straw length $Y_{1}$ and power consumption $Y_{2}$ of licorice stem after kneading and cutting under different structures and working parameters were used as evaluation indexes of kneading and cutting performance.

\subsubsection{Standard Straw Growth Rate}

The standard straw length rate was sampled by quartering method. Four samples were taken from each group of samples, each of $400 \mathrm{~g}$, and screened by Pennsylvania screens with holes of $19 \mathrm{~mm}, 8 \mathrm{~mm}, 5 \mathrm{~mm}$ and $0 \mathrm{~mm}$ (chassis) stacked from top to bottom according to aperture size. Refer to GB/T 26551-2011 roughage shredder to determine the standard grass length rate of licorice stem. The formula of the standard straw length rate in the standard is:

$$
S_{c}=\frac{m_{c}}{m_{y}} \times 100
$$

This equation has the following parameters:

$S_{c}$-Standard liquorice stem length ratio (\%);

$m_{c}$-Standard liquorice stem total mass $(\mathrm{g})$;

$m_{y}$-Total mass of sample (g).

\subsubsection{Power Consumption}

Total power of TMR mixer

$$
W=\frac{\sum_{i=1}^{\mu} U_{i} \sum_{i=1}^{\mu} I_{i} t}{\mu^{2}}
$$

where, $W$ is the total work of the TMR mixer, $\mathrm{J}$; $U$ is the input voltage, $\mathrm{V} ; \mathrm{I}$ is the input current, $\mathrm{A} ; t$ is time, $\mathrm{s} ; \mu$ is the number of torque data collected in a single test.

Motor power consumption

$$
W_{1}=T \omega t=2 \pi n_{1} t \frac{\sum_{i=1}^{\mu} T_{1 i}}{60 \mu}
$$


where, $W_{1}$ is the motor work consumption, $\mathrm{J} ; T_{1}$ is the motor torque, $\mathrm{N} \cdot \mathrm{m} ; n_{1}$ is the motor input speed, $\mathrm{r} / \mathrm{min} ; \mu$ is the number of torque data collected in a single test.

$$
T_{2}=\frac{9549 \times P_{1} \times i \times \epsilon}{n_{1}}
$$

where, $T_{2}$ is the reducer torque, $\mathrm{N} \cdot \mathrm{m} ; P_{1}$ is the motor power, $\mathrm{W} ; \mathrm{I}$ is deceleration ratio; $\epsilon$ is the usage coefficient.

$$
W_{2}=2 \pi n_{2} t \frac{\sum_{i=1}^{\mu} T_{2 i}}{60 \mu}
$$

where, $W_{2}$ is the power consumption of the reducer, $\mathrm{J} ; n_{2}$ is the output speed of the reducer, $\mathrm{r} / \mathrm{min}$.

Energy consumption of stem kneading and cutting in horizontal TMR mixer.

$$
W_{3}=W-W_{1}-W_{2}
$$

where, $W$ is the total work of the TMR mixer, $\mathrm{J} ; W_{1}$ is the motor power consumption, $\mathrm{J} ; W_{2}$ is the power consumption of the reducer, $\mathrm{J} ; W_{3}$ is the work consumption in the kneading and cutting process of licorice stem, $\mathrm{J}$.

According to the theoretical analysis and preliminary test, the auger speed, processing time and blade have a great influence on the rubbing and cutting effect of licorice culm. In order to ensure good palatability of licorice stem after kneading and cutting, and to improve the working efficiency of TMR mixer, the optimal parameter combination was sought to reduce power consumption. Speed of auger is 15 25 r/min. Processing time: 15 35 min; type of blade. According to Box-Behnken response surface design theory [31], standard straw length $Y_{1}$ and power consumption $Y_{2}$ were taken as response values to carry out three-factor and three-level response surface test. The test factors and levels are shown in Table 1.

Table 1. Factor level coding table.

\begin{tabular}{cccc}
\hline Level & $\begin{array}{c}\boldsymbol{X}_{\mathbf{1}} \text { Auger } \\
\text { Rotation/(r/min) }\end{array}$ & $\begin{array}{c}\boldsymbol{X}_{\mathbf{2}} \text { Process Time } \\
/(\mathbf{m i n})\end{array}$ & $\begin{array}{c}\boldsymbol{X}_{\mathbf{3}} \text { Type of Blades } \\
\text { (Proportion of Round } \\
\text { Blades in Total Blades) } \\
/(\mathbf{k g})\end{array}$ \\
\hline-1 & 15 & 15 & 0 \\
0 & 20 & 25 & 50 \\
1 & 25 & 35 & 100 \\
\hline
\end{tabular}

\subsection{Test Results and Analysis}

\subsubsection{The Test Results}

The three-factor and three-level Box-Behnken test was designed with design-expert 11.0 software. The test included 12 groups of analysis factors and 3 groups of zero estimation error, and a total of 15 groups of test points.

\subsubsection{Establishment of Regression Model and Significance Test}

Design-expert 11.0 software was used to analyze the data in Table 2 and perform multiple regression fitting. The results of variance analysis are shown in Table 3. Establish regression equations of $Y_{1}$ and $Y_{2}$ for $X_{1}, X_{2}$ and $X_{3}$, and test their significance. 
Table 2. Experimental scheme and results.

\begin{tabular}{cccccc}
\hline $\begin{array}{c}\text { Order } \\
\text { Number }\end{array}$ & $\boldsymbol{X}_{\mathbf{1}}$ & $\boldsymbol{X}_{\mathbf{2}}$ & $\boldsymbol{X}_{\mathbf{3}}$ & $\begin{array}{c}\text { Standard Grass } \\
\text { Length Ratio (\%) } \\
\boldsymbol{Y}_{\mathbf{1}}\end{array}$ & $\begin{array}{c}\text { The Power } \\
\text { Consumption } \\
\mathbf{( k J )} \boldsymbol{Y}_{\mathbf{2}}\end{array}$ \\
\hline 1 & 15 & 15 & 50 & 54.69 & 1897.83 \\
2 & 25 & 15 & 50 & 71.94 & 2899.3 \\
3 & 15 & 35 & 50 & 78.56 & 4385.75 \\
4 & 25 & 35 & 50 & 84.44 & 6895.44 \\
5 & 15 & 25 & 0 & 78.19 & 3226.33 \\
6 & 25 & 25 & 0 & 85.44 & 4971.82 \\
7 & 15 & 25 & 100 & 60.81 & 3109.32 \\
8 & 25 & 25 & 100 & 73.86 & 4731.95 \\
9 & 20 & 15 & 0 & 71.44 & 2377.81 \\
10 & 20 & 35 & 0 & 86.25 & 5462.19 \\
11 & 20 & 15 & 100 & 58.31 & 2290.72 \\
12 & 20 & 35 & 100 & 80.13 & 5414.63 \\
13 & 20 & 25 & 50 & 78.69 & 3982.21 \\
14 & 20 & 25 & 50 & 79.69 & 4055.67 \\
15 & 20 & 25 & 50 & 78.94 & 3924.78 \\
\hline
\end{tabular}

Table 3. Regression equation analysis of variance.

\begin{tabular}{|c|c|c|c|c|c|c|}
\hline $\begin{array}{l}\text { Simulation } \\
\text { Item }\end{array}$ & Sum of Square & $\begin{array}{l}\text { Degree of } \\
\text { Freedom }\end{array}$ & $\begin{array}{c}\text { Mean Square } \\
\text { Error }\end{array}$ & $F$ Value & $p$ Value & Sum of Square \\
\hline \multirow{14}{*}{$Y_{1}$} & model & 1362.45 & 9 & 151.38 & 67.44 & 0.0001 \\
\hline & $\mathrm{X}_{1}$ & 235.77 & 1 & 235.77 & 105.03 & 0.0002 \\
\hline & $x_{2}$ & 684.50 & 1 & 684.50 & 304.92 & $<0.0001$ \\
\hline & $x_{3}$ & 302.70 & 1 & 302.70 & 134.84 & $<0.0001$ \\
\hline & $X_{1} X_{2}$ & 32.32 & 1 & 32.32 & 14.40 & 0.0127 \\
\hline & $x_{1} X_{3}$ & 8.41 & 1 & 8.41 & 3.75 & 0.1107 \\
\hline & $x_{2} X_{3}$ & 16.04 & 1 & 16.04 & 7.15 & 0.0442 \\
\hline & $\mathrm{X}_{1}^{2}$ & 32.20 & 1 & 32.20 & 14.35 & 0.0128 \\
\hline & $\mathrm{X}_{2}^{2}$ & 51.81 & 1 & 51.81 & 23.08 & 0.0049 \\
\hline & $x_{3}^{2}$ & 9.20 & 1 & 9.20 & 4.10 & 0.0988 \\
\hline & Residual & 11.22 & 5 & 2.24 & & \\
\hline & Lack of fit & 10.68 & 3 & 3.56 & 13.15 & 0.0715 \\
\hline & Pure error & 0.5417 & 2 & 0.2708 & & \\
\hline & sum & 1373.67 & 14 & & & \\
\hline \multirow{14}{*}{$Y_{2}$} & model & $2.67 \times 10^{7}$ & 9 & $2.96 \times 10^{6}$ & 552.54 & $<0.0001$ \\
\hline & $X_{1}$ & $5.92 \times 10^{6}$ & 1 & $5.92 \times 10^{6}$ & 1101.76 & $<0.0001$ \\
\hline & $X_{2}$ & $2.01 \times 10^{7}$ & 1 & $2.01 \times 10^{7}$ & 3750.48 & $<0.0001$ \\
\hline & $X_{3}$ & $30,200.22$ & 1 & $30,200.22$ & 5.62 & 0.0638 \\
\hline & $X_{1} X_{2}$ & $5.69 \times 10^{5}$ & 1 & $5.69 \times 10^{5}$ & 105.92 & 0.0001 \\
\hline & $X_{1} X_{3}$ & 3773.64 & 1 & 3773.64 & 0.7028 & 0.4401 \\
\hline & $X_{2} X_{3}$ & 390.66 & 1 & 390.66 & 0.0728 & 0.7981 \\
\hline & $X_{1}^{2}$ & $22,332.91$ & 1 & $22,332.91$ & 4.16 & 0.0969 \\
\hline & $X_{2}^{2}$ & 7726.68 & 1 & 7726.68 & 1.44 & 0.2840 \\
\hline & $X_{3}^{2}$ & $11,361.11$ & 1 & $11,361.11$ & 2.12 & 0.2055 \\
\hline & Residual & $26,845.89$ & 5 & 5369.18 & & \\
\hline & Lack of fit & $18,236.96$ & 3 & 6078.99 & 1.41 & 0.4401 \\
\hline & Pure error & 8608.92 & 2 & 4304.46 & & \\
\hline & sum & $2.67 \times 10^{7}$ & 14 & & & \\
\hline
\end{tabular}




\section{Significance Analysis of Standard Straw Length}

The results of standard straw length rate variance analysis are shown in Table 3. $Y_{1}$ model $p=0.0001$, indicating that this regression model is extremely significant, and its absolute coefficient $R^{2}$ value is 0.99 , indicating that this model can fit more than $99 \%$ of the test results. Among them, $X_{1}, X_{2}, X_{3}$ and $X_{2}^{2}$ have extremely significant effects on the standard straw length rate model, $X_{1} X_{2}, X_{2} X_{3}$ and $X_{1}{ }^{2}$ have significant effects on the standard straw length rate model, and $X_{3}^{2}$ has significant effects on the standard straw length rate model. The significance of each variable on the standard straw length from large to small was processing time, blade type and auger speed. After eliminating the insignificant factors, the quadratic regression equation of each variable to particle size is shown in Equation (39).

$$
\begin{aligned}
& Y_{1}=79.11+5.43 X_{1}+9.25 X_{2}-6.15 X_{3}-2.85 X_{1} X_{2} \\
& +2 X_{2} X_{3}-2.95 X_{1}^{2}-3.75 X_{2}^{2}-1.58 X_{3}^{2}
\end{aligned}
$$

Power Significance Impact

Power variance analysis results are shown in Table $3, Y_{2}$ model $p<0.0001$, indicating that the regression model is extremely significant, and its absolute coefficient $R^{2}$ value is 0.99 , indicating that the model can fit more than $99 \%$ of the test results. Among them, $X_{1}$, $X_{2}$ and $X_{1} X_{2}$ had a very significant effect on the model of breakage rate, while $X_{3}$ and $X_{1}{ }^{2}$ had a more significant effect on the standard straw length pattern. The significance of each variable on the breakage rate from large to small is auger speed, processing time and blade type. After eliminating the insignificant factors, the quadratic regression equation of factor value of each variable to particle size is shown in Equation (40).

$$
\begin{aligned}
& Y_{2}=3987.55+859.91 X_{1}+61.44 X_{3} \\
& +377.06 X_{1} X_{2}+77.77 X_{1}^{2}
\end{aligned}
$$

\subsubsection{Influence of Interaction Factors on Kneading and Cutting Performance}

Design-expert 11.0 software was used to generate the response surface diagram of the model, as shown in Figure 5. Analyze $X_{1}$ and $X_{2}$ according to the response surface and the influence rule of interaction factors of $X_{3}$ on response values $Y_{1}$ and $Y_{2}$.

Influence Analysis of Standard Straw Length

In Figure 5, a shows the corresponding surface curves of $X_{1}$ and $X_{2}$ interaction with $Y_{1}$. When the auger speed and processing time increased, the standard straw length rate increased first and then decreased.

When the auger's rotating speed increased, the cutting effect of the blade on the licorice stem and the frequency of the auger rubbing the licorice stem were accelerated, and the cutting effect of the licorice stem was enhanced, and the times of force were increased. When the processing time of auger increases, the cutting time of licorice stem increases, the standard grass length increases gradually, and the cutting effect of licorice stem increases. When the auger speed and processing time reach the maximum level, the standard straw length reaches the maximum. However, as the auger speed continues to increase, the casting effect of licorice stems becomes more and more obvious, and fewer stalks fall to the bottom of the box and enter the rubbing area, and the standard straw length rate decreases slowly. With the increase of processing time, the proportion of fine powder produced by cutting and kneading of licorice stem increased, while the standard grass length decreased slowly. 


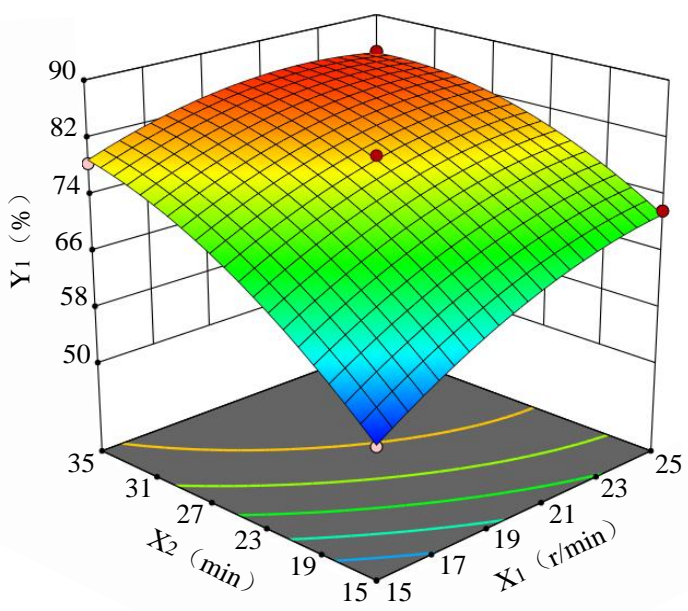

a

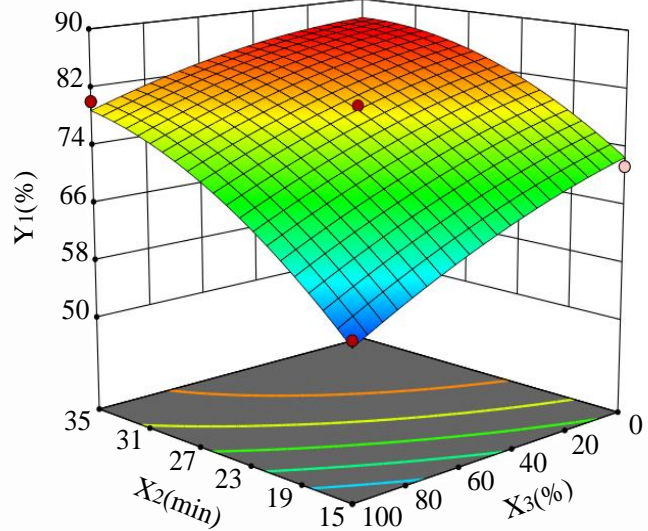

b

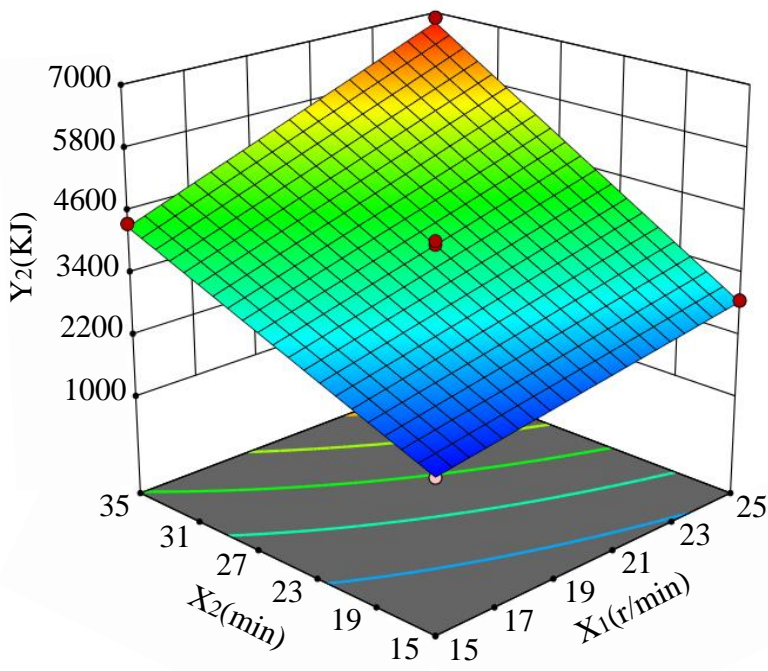

c

Figure 5. Interaction effects of interaction factors on standard straw length $Y_{1}$ and power consumption $Y_{2}$. (a) Interaction response surface diagram of processing time and auger speed on standard straw length. (b) Interaction response surface diagram of processing time and blade type on standard straw length (c) Interaction response surface diagram of auger speed and processing time on power consumption.

In Figure $5, b$ shows the corresponding surface curves of $X_{2}$ and $X_{3}$ interacting with $Y_{1}$. As can be seen from the figure, when the processing time and the proportion of plum blade in the total blade increases, the standard straw length rate firstly increases and then decreases.

With the increase of processing time, the rubbing and cutting time of blade and spiral blade on licorice stem increased, and the standard straw length increased gradually. With the decrease of the ratio of round blades to total blades, the number of plum blades increased, the blade area of glycyrrhiza root stalk contacting blade increased, and the shear force of glycyrrhiza root stalk increased. When the processing time and the proportion of plum blade reaches the maximum level, the standard straw length reaches the maximum. However, as the processing time continued to increase, the fine powder rate of liquorice stem kneading and cutting increased, the average times of action on materials per unit time decreased, and the standard straw length rate decreased slowly. 


\section{Influence Analysis of Power Consumption}

In Figure 5, c shows the corresponding surface curves of the interaction between $X_{1}$ and $X_{2}$ on $Y_{2}$. As can be seen from the figure, when the auger speed and processing time increase, the power consumption increases. When the auger speed increases, the blade shear frequency of glycyrrhiza stem increases, and the contact frequency of glycyrrhiza stem and spiral auger shaft, shell and spiral blade increases in unit time, and the contact area increases. The friction between licorice stem and auger shaft, shell and blade increases and power consumption increases. When the processing time increases, the contact frequency between licorice stem and auger shaft, shell and spiral blade becomes higher, and the cutting times of blade on licorice stem increase, and the power consumption increases.

\subsection{Test Results and Analysis}

In order to achieve the best performance of TMR mixer in the process of liquorice kneading and cutting, the influencing factors in the experiment were optimized. According to machine working conditions, performance requirements and the above analysis results. DesignExpert-v11.0.3 software was used to optimize and analyze the model, and the constraint conditions were

$$
\left\{\begin{array}{cl}
15 & \leq X_{1} \leq 25 \\
15 & \leq X_{2} \leq 35 \\
0 & \leq X_{3} \leq 100 \\
85 & \leq Y_{1} \leq 100 \\
1897.83 & \leq Y_{2} \leq 5000
\end{array}\right.
$$

The results show that the auger speed is $20.03 \mathrm{r} / \mathrm{min}$, the processing time is $28.88 \mathrm{~min}$, and the proportion of plum blade in the total blade is $100 \%$. At this time, the standard straw length was $85.945 \%$; Net power consumption $4654.571 \mathrm{~kJ}$, TMR mixer performance reached the best. In order to verify the accuracy of the model, based on the test conditions, the rounding speed was $20 \mathrm{r} / \mathrm{min}$, the processing time was $29 \mathrm{~min}$, and the type of blade was quincun $x$ blade. Three tests were conducted for verification, and the average value was taken. The results are shown in Table 4.

Table 4. Comparison between model optimization value and validation test value.

\begin{tabular}{ccc}
\hline Item & $\boldsymbol{Y}_{\mathbf{1}} / \%$ & $\boldsymbol{Y}_{\mathbf{2}} / \mathbf{k J}$ \\
\hline Item optimization value & 85.945 & 4654.571 \\
Validation test value & 82.634 & 4525.815 \\
The relative error & 3.85 & 2.77 \\
\hline
\end{tabular}

By verifying the test results, it can be seen that the error between the theoretical optimization value of the model and the experimental value is less than $4 \%$, and the optimization model is reasonable and feasible, meeting the operation requirements.

\section{Conclusions}

(1) The work consumption in the working process is analyzed by the material element, and the influences of the auger speed, processing time and other factors on the working effect of the mixer are determined.

(2) Response surface experiment was carried out to establish a quadratic multinomial influence model of standard straw length ratio and power consumption on three factors and three levels. It is concluded that the significant effect of each factor on the standard straw length is from large to small: processing time, blade type, auger speed; the significance of the influence on power consumption from large to small is auger speed, processing time and blade type. The influence trends of auger speed, processing time and blade type on standard straw length and power consumption of liquorice after rubbing and cutting were analyzed. 
(3) The Box-Behnken combination test method was used to optimize and analyze the optimal working parameters of the horizontal dual-axis TMR mixer. The auger speed was $20 \mathrm{r} / \mathrm{min}$, the processing time was $29 \mathrm{~min}$, and the quine blade was selected for verification test. The final standard straw length was $82.634 \%$. The net power consumption is $4525.815 \mathrm{~kJ}$, and the relative error is less than $4 \%$ compared with the prediction model. The model is reliable and can meet the operation requirements.

Author Contributions: Conceptualization, B.W. and J.Z.; methodology, J.L. (Jingbin Li); software, P.S.; validation, J.L. (Junpeng Liang), T.L. and B.Q.; formal analysis, W.L.; investigation, Y.S.; resources, W.L.; data curation, W.L.; writing-original draft preparation, W.L.; writing-review and editing, B.W.; visualization, J.Z.; supervision, W.L.; project administration, W.L.; funding acquisition, J.L. (Jingbin Li). All authors have read and agreed to the published version of the manuscript.

Funding: The project was supported by the National Natural Science Foundation of China (51775358) and the Task of Post Experts in The Technical System of Breeding and Promotion of High-efficiency Mutton Sheep Breeds in Autonomous Region (XJNQRY-G-2107).

Institutional Review Board Statement: Not applicable.

Informed Consent Statement: Not applicable.

Data Availability Statement: Not applicable.

Conflicts of Interest: The authors declare no conflict of interest. The funders had no role in the design of the study; in the collection, analyses, or interpretation of data; in the writing of the manuscript, or in the decision to publish the results.

\section{References}

1. Xu, M.; Chao, X.; Zhang, B. Study on the investigation, analysis and countermeasures for the current status of mutton sheep industry in Xinjiang. J. Domest. Anim. Ecol. 2018, 39, 85-89. [CrossRef]

2. Xin, J. Revitalize the agricultural area animal husbandry to help Xinjiang poverty alleviation. Rural Sci. Technol. 2021, 12, 47-49. [CrossRef]

3. Li, Y.; Wang, M.; Wen, B.; Li, J.; Li, L.; Kan, Z. Experimental study on the mechanical properties of Glycyrrhiza stem on the grey correlation theory. J. Chin. Agric. Mech. 2021, 42, 72-78. [CrossRef]

4. Zheng, H.; Ting, L.; Yun, G.; Xiao, J.; Xiu, P.; Yi, T.; Jin, J. A Systematic Review of the Anticancer Properties of Compounds Isolated from Licorice. Planta Med. 2015, 81, 1670-1687.

5. Mehdinejadiani, K.; Shirzad, H.; Fakhari, S. An Evaluation the Effect of Glycyrrhetinic and Glycyrrhizic Acids Derived from Licorice Extract on Gastric Cancer Cell Lines. J. Babol Univ. Med Sci. 2015, 17, 53-59.

6. Sedghi, M.; Golian, A.; Kermanshahi, H.; Ahmadi, H. Effect of dietary supplementation of licorice extract and a prebiotic on performance and blood metabolites of broilers. S. Afr. J. Anim. Sci. 2010, 40. [CrossRef]

7. Liu, Y.; Han, X.; Chen, L. Licorice Resources and Its Exploitation in Xinjiang. Food Res. Dev. 2012, 33, 209-212. [CrossRef]

8. Gao, Z.; Li, H.; Meng, H. Study on concentrated precise feeding pattern based on feeding technology of TMR. Trans. Chin. Soc. Agric. Eng. 2013, 29, 148-154. [CrossRef]

9. Li, D.; Wang, S.; Gao, Y.; Qin, L.; Fu, J. Preliminary Study on Total Mixed Ration Nutrition Standards for Mutton Sheep Breeding. Chin. J. Anim. Nutr. 2019, 31, 4092-4098. [CrossRef]

10. Tian, F.; Chen, Y.; Song, Z.; Yan, Y.; Li, F.; Wang, Z. Design and Experiment of Self-propelled TMR Preparation Mixer for Silage Straw Feed. Trans. Chin. Soc. Agric. Mach. 2020, 51, 106-114.

11. Annamaria, C.; Alessandro, A.; Vera, P.; Giovanni, S.; Massimo, L.; Stefano, N. Francesco Maria Tangorra. Influence of different loading levels, cutting and mixing times on total mixed ration (TMR) homogeneity in a vertical mixing wagon during distribution: A case study. Ital. J. Anim. Sci. 2019, 18, 1093-1098.

12. Warguła, Ł.; Kukla, M.; Wieczorek, B.; Krawiec, P. Energy consumption of the wood size reduction processes with employment of a low-power machines with various cutting mechanisms. Renew. Energy 2022, 181, 630-639. [CrossRef]

13. Gao, Y.; Kang, F.; Kan, J.; Wang, Y.; Tong, S. Analysis and Experiment of Cutting Mechanical Parameters for Caragana korshinskii (C.K.) Branches. Forests 2021, 12, 1359. [CrossRef]

14. Petrov, E.P. Analytical Formulation of Friction Contact Elements for Frequency-Domain Analysis of Nonlinear Vibrations of Structures with High-Energy Rubs. J. Eng. Gas Turbines Power 2019, 141, 121006. [CrossRef]

15. Wen, B.; Wang, K.; Kan, Z.; Li, J.; Li, L.; Liu, S. Design and experiments of segmented helical kneading and cutting device for licorice straw. Trans. Chin. Soc. Agric. Eng. 2020, 36, 1-11. [CrossRef]

16. Xie, F.; Li, J.; Kan, Z.; Wang, X. Design of self-propelled stirring feeder for mutton sheep. Xinjiang Agric. Mech. 2012, 10-12. [CrossRef] 
17. Wang, D.; Jiang, Y. The experimental study on the twin-shaft horizontal total mixed ration mixer. Trans. Chin. Soc. Agric. Eng. 2006, 22, 85-88.

18. Moallem, U.; Lifshitz, L. Accuracy and homogeneity of total mixed rations processed through trailer mixer or self-propelled mixer, and effects on the yields of high-yielding dairy cows. Anim. Feed. Sci. Technol. 2020, 270, 114708. [CrossRef]

19. Pezo, L.; Pezo, M. The joint mixing action of the static pre-mixer and the rotating drum mixer-Discrete element method approach. Adv. Powder Technol. 2018, 29, 1734-1741. [CrossRef]

20. Marczuk, A.; Sysuev, V.; Aleshkin, A. Theoretical Studies of the Interaction between Screw Surface and Material in the Mixer. Materials 2021, 14, 962. [CrossRef]

21. Wang, M.; Xu, Q.; Jiang, E.; Ren, Y.; Wu, Y.; Chen, X. Design and pilot test for feeder of biomass shaftless screw continuous pyrolysis device. Trans. Chin. Soc. Agric. Eng. 2017, 33, 83-88. [CrossRef]

22. Zhang, X.; Liu, Y.; Li, L.; Tong, W.; Yang, D.; Hou, C. Design and performance experiment of multi-segment type auger in process of organic fertilizer production. Trans. Chin. Soc. Agric. Eng. 2018, 34, 49-56. [CrossRef]

23. Wu, L.; Qing, L.; Wang, C. Design of screw-pneumatic coupling conveying device for crushed corn straw. Trans. Chin. Soc. Agric. Eng. 2019, 35, 29-38. [CrossRef]

24. Zhao, X.; He, Y.; Yuan, Z.; Kang, X. The Design and Research on the QH-5 Clipping and Mixing Machine. J. Agric. Mech. Res. 2008, 89-90, 94. [CrossRef]

25. Jiang, Y. Design and manufacture of auger. Pet. Eng. Constr. 2005, 71-72. [CrossRef]

26. Xie, F. The Structure Design and Research of Feeding and Mixing Blender for Mutton Sheep; Shihezi University: Shihezi, China, 2014.

27. Wu, L. Study on the Mechanism of Screw Conveying Theory for Rubbing and Breaking Corn Straw; Inner Mongolia Agricultural University: Hohhot, China, 2016.

28. Wang, D. Experiment on influencing factors of processing quality of biaxial horizontal diet mixing machine. Trans. Chin. Soc. Agric. Mach. 2007, 38, 208-210, 204.

29. Andreas, H.; Katharina, Z.; Birgit, F. Feeding forages with reduced particle size in a total mixed ration improves feed intake, total tractdigestibility, and performance of organic dairy cows. J. Dairy Sci. 2019, 102, 8839-8849.

30. Standardization Administration of China. Forage Kneading Machine: GB/T 20788-2006; Standards Press of China: Beijing, China, 2006.

31. Fu, J.; Zhang, J.; Wang, Z. Experimental Design and Analysis; Posts and Telecommunications Press: Beijing, China, 2009. 